Article

\title{
Precipitation Atlas for Germany (GePrA)
}

\author{
Christopher Jung * and Dirk Schindler \\ Environmental Meteorology, Albert-Ludwigs-University of Freiburg, Werthmannstrasse 10, \\ D-79085 Freiburg, Germany; dirk.schindler@meteo.uni-freiburg.de \\ * Correspondence: christopher.jung@mail.unr.uni-freiburg.de; Tel.: +49-761-203-3589
}

Received: 25 October 2019; Accepted: 20 November 2019; Published: 23 November 2019

\begin{abstract}
A new approach for modeling daily precipitation $(R R)$ at very high spatial resolution $(25 \mathrm{~m}$ $\times 25 \mathrm{~m}$ ) was introduced. It was used to develop the Precipitation Atlas for Germany (GePrA). GePrA is based on $2357 R R$ time series measured in the period 1981-2018. It provides monthly percentiles $(p)$ of the large-scale $R R$ patterns which were mapped by a thin plate spline interpolation (TPS). A least-squares boosting (LSBoost) approach and orographic predictor variables (PV) were applied to integrate the small-scale precipitation variability in GePrA. Then, a Weibull distribution (Wei) was fitted to $R R_{p}$. It was found that the mean monthly sum of $R R\left(\overline{R R}_{\text {sum }}\right)$ is highest in July $(84 \mathrm{~mm})$ and lowest in April (49 mm). A great dependency of $R R$ on the elevation $(\varepsilon)$ was found and quantified. Model validation at 425 stations showed a mean coefficient of determination $\left(R^{2}\right)$ of 0.80 and a mean absolute error $(M A E)$ of less than $10 \mathrm{~mm}$ in all months. The high spatial resolution, including the effects of the local orography, make GePrA a valuable tool for various applications. Since GePrA does not only describe $\overline{R R}_{\text {sum }}$, but also the entire monthly precipitation distributions, the results of this study enable the seasonal differentiation between dry and wet period at small scales.
\end{abstract}

Keywords: Weibull distribution; least-squares boosting; annual cycle; thin plate spline interpolation

\section{Introduction}

Precipitation impacts the environment in a number of ways. It drives the water cycle by determining the availability of water [1] and by affecting the exchange of water between the atmosphere and the land surface [2]. With increasing intensity, precipitation may trigger floods and increase soil vulnerability to erosion [3]. Many sectors, including forestry, agriculture, water resource management, food security, hydropower, and disaster management, depend on the spatiotemporal dynamics of precipitation regimes [2,4]. Thus, they are in need of accurate, local information on the statistical properties of precipitation [5].

However, the high spatiotemporal variability of precipitation is a major constraint for the statistical description of precipitation distributions [6]. On spatial scales, precipitation patterns are influenced by the orography [6-10] and land cover [11,12]. On temporal scales, precipitation patterns are driven by different temporal cycles of the large-scale atmospheric circulation [13] and diurnal warming [14].

To statistically consider the complexity of precipitation regimes in large areas, a large number of long-term precipitation measurements is required. Unfortunately, the density of precipitation gauges is often too sparse for a detailed representation of the small-scale precipitation variability $[1,7,15]$. Precipitation models with a high spatial resolution can fill the gaps that occur in low-density networks [16]. In general, the modeling approaches can be differentiated into two categories: (1) Atmospheric circulation models and (2) statistical models. Atmospheric circulation models are useful tools for characterizing and investigating physical processes leading to precipitation. Applying atmospheric circulation models requires deep knowledge of a large number of input parameters. Their initialization and parameterization can thus be very complex. 
In contrast, statistical models are based on precipitation measurements and a variety of predictor variables associated with the precipitation pattern in certain regions. Statistical approaches do not provide deep insight into the underlying physical processes driving precipitation formation but can describe the precipitation pattern at a very high spatial resolution, even when only a limited number of precipitation measuring stations exists [8].

There are numerous investigations on the parameterization of statistical precipitation models. For instance, a linear regression model was developed to describe the variability of winter precipitation in Great Britain [17]. In another study, the monthly precipitation was modeled at a spatial resolution of $1 \mathrm{~km} \times 1 \mathrm{~km}$ by applying a statistical downscaling approach [1]. Recently, a method for stochastic simulation of precipitation was developed based on a linear theory, which described the orographic precipitation and additional functions that consider synoptic and convective precipitation [18]. Statistical downscaling techniques were also used to build a precipitation model using satellite and land surface data [19].

Based on currently known statistical approaches, a model was developed in this study which enabled the mapping of the entire statistical precipitation distribution at a very high spatial resolution $(25 \mathrm{~m} \times 25 \mathrm{~m})$ in a large study area. To depict the annual cycle of the precipitation regime, the model was monthly parameterized. For model development, a theoretical distribution capable to accurately mimic the empirical precipitation distribution was found, which made it possible to quantify the strong dependence of precipitation on elevation $(\varepsilon)$.

\section{Material and Methods}

\subsection{Overview}

The development of GePrA was composed of the following main steps (Figure 1): (1) Obtaining daily precipitation data (parametrization data) provided by the German Meteorological Service for the period 1981-2018; (2) fitting of 18 theoretical distributions to the precipitation time series and evaluation of their goodness-of-fit; (3) building of predictor variables representing the local orography based on a digital elevation model; (4) high spatial resolution modeling $(25 \mathrm{~m} \times 25 \mathrm{~m})$ of the percentiles by a least-squares boosting approach and thin plate spline interpolation; (5) fitting of Weibull distributions, which provide the best fits, to the modeled precipitation percentiles; and (6) model validation by independent precipitation data (validation data).

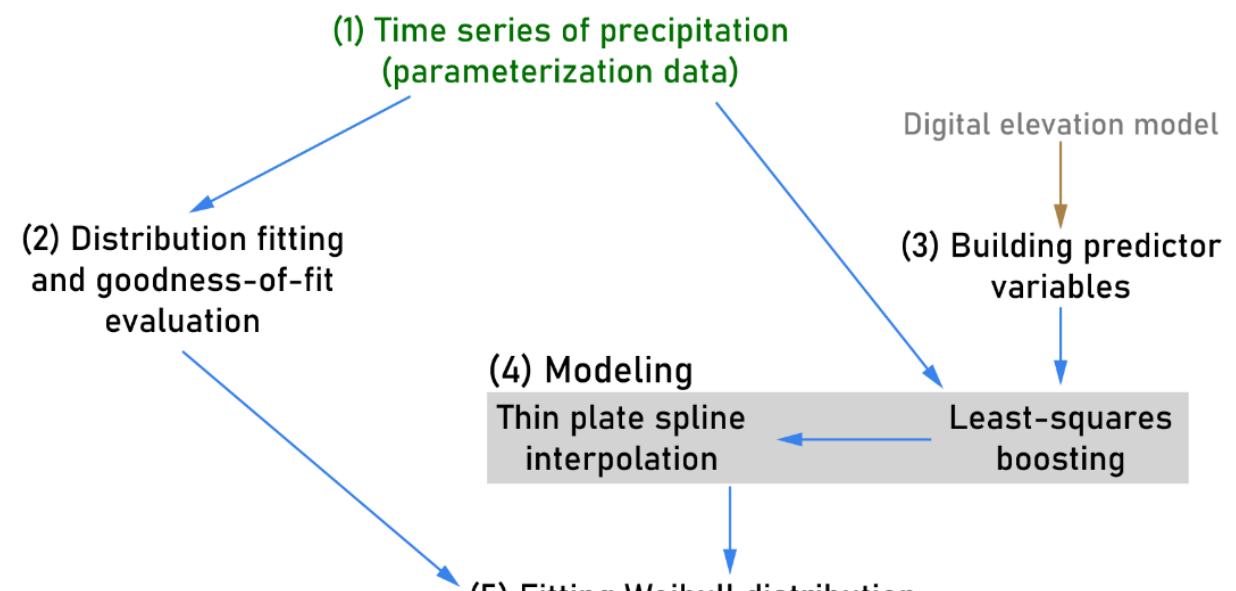

(5) Fitting Weibull distribution

Time series of precipitation (validation data) (6) Model validation

Figure 1. Overview of the methodology applied to develop the Precipitation Atlas for Germany (GePrA). 


\subsection{Study Area and Precipitation Data}

Germany has a size of about $357,000 \mathrm{~km}^{2}$. The country consists of the four large natural areas: The North German Plain, Central German Plain, Alpine Foothills, and Alps in southern Germany [20]. Its topography is complex and $\varepsilon$ ranges from below $0 \mathrm{~m}$ to nearly $3000 \mathrm{~m}$ (Figure 2). Besides the high mountain range of the Alps, there are numerous low mountain ranges (500 $\mathrm{m}<\varepsilon<1500 \mathrm{~m}$ ). The highest and largest contiguous low mountain range is the Black Forest in the southwest.

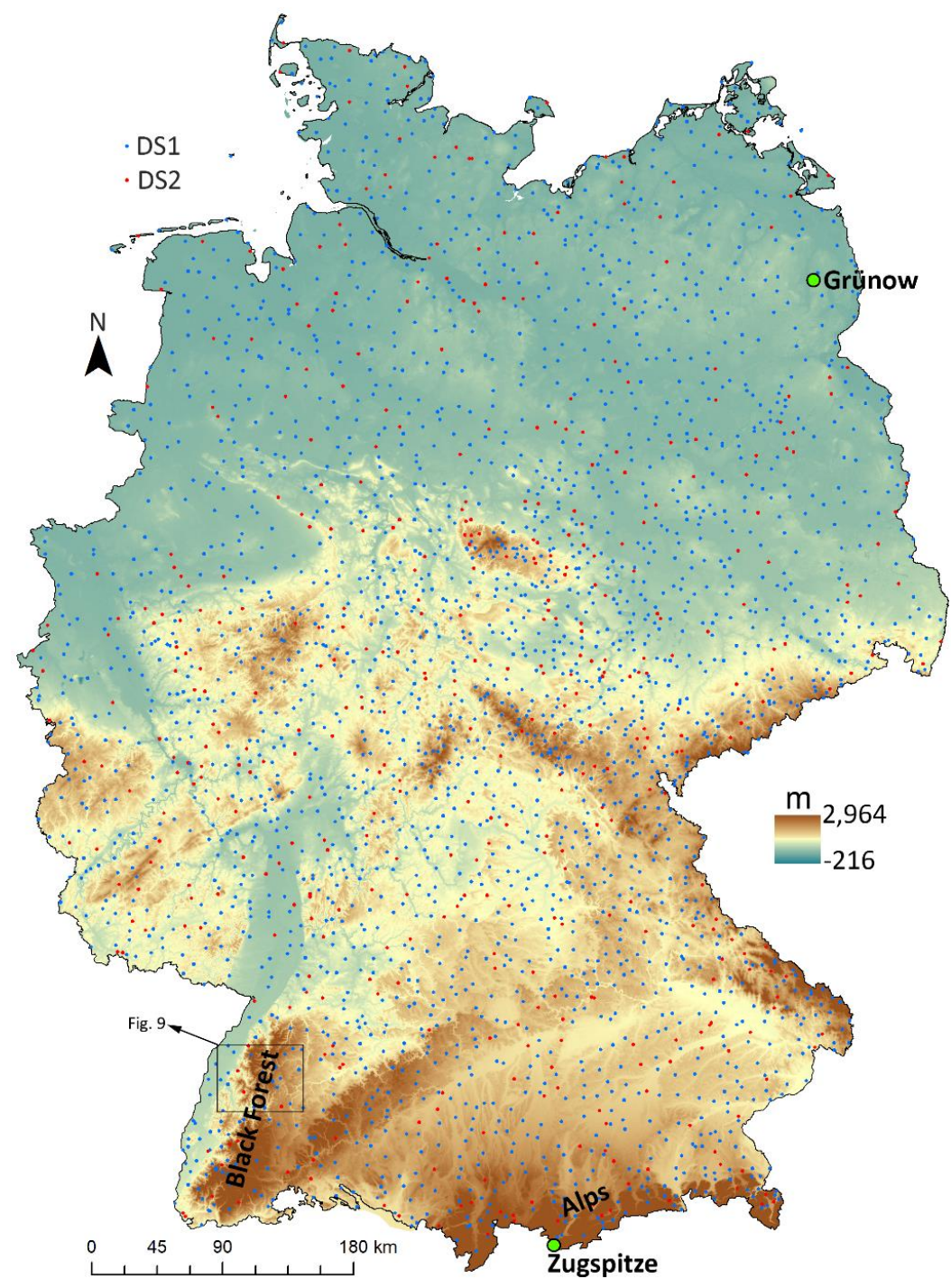

Figure 2. Precipitation $(R R)$ measurement sites subdivided into a parameterization dataset (DS1) and validation dataset (DS2). Elevation $(\varepsilon)$ in the study area varies between $-216 \mathrm{~m}$ and $2964 \mathrm{~m}$ (top of the mountain Zugspitze). For the points labeled "Grünow" and "Zugspitze", more results are presented in Figure 5. The figure inset highlights a region in the Black Forest for which detailed results are presented in Figure 9.

The study was based on daily precipitation $(R R)$ measurements of the period 1981-2018 available from the German Meteorological Service climate data center [21]. Depending on the availability of $R R$ data $(D A), R R$ time series were assigned to either the parameterization dataset (DS1) or to the validation dataset (DS2). DS1 contained $2357 R R$ time series with $D A>50 \%$. DS2 included $425 R R$ time series with $D A$ being in the range of $40.0 \%$ to $49.9 \%$. All other and less complete time series were not considered for further analysis. 


\subsection{Distribution Fitting}

The selection of suitable theoretical distributions is of great importance for the accurate description of the statistical properties of precipitation time series. Thus, different statistical distributions used in previous studies $[22,23]$ were tested. From these distributions, those with less than four parameters were selected (Table 1). The distributions were fitted to monthly empirical cumulative distribution functions (ecdf) of $R R$ included in DS1 by applying the maximum likelihood method. As there is often a very high proportion of $R R=0 \mathrm{~mm}$, the distributions were only fitted to $R R>0 \mathrm{~mm}$. The goodness-of-fit ( $\mathrm{GoF}$ ) of each theoretical distribution was assessed by the Kolmogorov-Smirnov statistic $(K S)$, the coefficient of determination related to the cumulative probability $\left(R_{P P}^{2}\right)$, and the coefficient of determination related to the quantiles $\left(R_{Q Q}^{2}\right)[24]$.

Table 1. Theoretical distributions fitted to daily precipitation $(R R)$ including their parameters [25].

\begin{tabular}{ccc}
\hline Distribution & Abbreviation & Parameters \\
\hline Beta & Be & shape, shape \\
Birnbaum-Saunders & $\mathrm{BS}$ & shape, scale \\
Burr & $\mathrm{Bu}$ & shape, shape, scale \\
Epsilon Skew Normal & $\mathrm{ESN}$ & scale, location, skewness \\
Extreme Value & $\mathrm{EV}$ & location, scale \\
Gamma & Gam & shape, scale \\
Generalized Extreme Value & GEV & shape, scale, location \\
Generalized Pareto & $\mathrm{GP}$ & shape, scale, location \\
Inverse Gaussian & $\mathrm{IG}$ & scale, shape \\
Logistic & $\mathrm{L}$ & mean, scale \\
Log-logistic & $\mathrm{LL}$ & mean, scale (of logarithmic values) \\
Lognormal & $\mathrm{LN}$ & shape, scale \\
Nakagami & $\mathrm{Na}$ & mean, standard deviation \\
Normal & $\mathrm{N}$ & mean \\
Poisson & $\mathrm{P}$ & non-centrality, scale \\
Rician & $\mathrm{R}$ & location, scale, shape \\
t-Location Scale & tLS & shape, scale \\
Weibull & Wei &
\end{tabular}

The distribution fitting was made using Mathworks' Matlab ${ }^{\circledR}$ Software Statistics and Machine Learning Toolbox (Release 2019a; The MathWorks Inc., Natick, MA, USA).

\subsection{Predictor Variables}

The orographic features (Table 2) were represented by 22 predictor variables (PV) derived from the digital elevation model EU-DEM v.1 at a $25 \mathrm{~m} \times 25 \mathrm{~m}$ spatial resolution [26]. The relative elevation $(\eta)$ was developed by subtracting the mean elevation of an outer circle of each grid cell from the grid cell-specific $\varepsilon$ value [27]. Four $\eta$ variants with outer-circle radii of $1000 \mathrm{~m}\left(\eta_{1000}\right), 3000 \mathrm{~m}\left(\eta_{3000}\right), 5000$ $\mathrm{m}\left(\eta_{5000}\right)$, and $7500 \mathrm{~m}\left(\eta_{7500}\right)$ were built. For the eight main compass directions, $\eta$ was modeled with a $3000 \mathrm{~m}$ radius. Furthermore, the orographic sheltering $(\sigma)$ was quantified. It was derived by calculating the angles between grid cell-specific elevation and the visible horizon up to a distance of $1000 \mathrm{~m}$ [27].

Table 2. Orographic features used as predictor variables (PV) for modeling daily precipitation $(R R)$.

\begin{tabular}{ccccc}
\hline Symbol & Name & Sector $\left(^{\circ}\right)$ & Distance $(\mathbf{m})$ & Data Source \\
\hline lon & longitude & - & - & - \\
lat & latitude & - & - & - \\
$\varepsilon$ & elevation & - & - & EU-DEM v.1 \\
$\eta_{1000}$ & relative elevation & $1-360$ & 1000 & EU-DEM v.1 \\
$\eta_{3000}$ & relative elevation & $1-360$ & 3000 & EU-DEM v.1 \\
\hline
\end{tabular}


Table 2. Cont.

\begin{tabular}{ccccc}
\hline Symbol & Name & Sector $\left.\mathbf{(}^{\circ}\right)$ & Distance $(\mathbf{m})$ & Data Source \\
\hline$\eta_{5000}$ & relative elevation & $1-360$ & 5000 & EU-DEM v.1 \\
$\eta_{7500}$ & relative elevation & $1-360$ & 7500 & EU-DEM v.1 \\
$\eta_{n}$ & relative elevation & $337.5-22.4$ & 3000 & EU-DEM v.1 \\
$\eta_{n e}$ & relative elevation & $22.5-67.4$ & 3000 & EU-DEM v.1 \\
$\eta_{e}$ & relative elevation & $67.5-112.4$ & 3000 & EU-DEM v.1 \\
$\eta_{s e}$ & relative elevation & $112.5-157.4$ & 3000 & EU-DEM v.1 \\
$\eta_{s}$ & relative elevation & $157.5-202.4$ & 3000 & EU-DEM v.1 \\
$\eta_{s w}$ & relative elevation & $202.5-247.4$ & 3000 & EU-DEM v.1 \\
$\eta_{w}$ & relative elevation & $247.5-292.4$ & 3000 & EU-DEM v.1 \\
$\eta_{n w}$ & relative elevation & $292.5-337.4$ & 3000 & EU-DEM v.1 \\
$\sigma_{n}$ & sheltering & $337.5-22.4$ & 1000 & EU-DEM v.1 \\
$\sigma_{n e}$ & sheltering & $22.5-67.4$ & 1000 & EU-DEM v.1 \\
$\sigma_{e}$ & sheltering & $67.5-112.4$ & 1000 & EU-DEM v.1 \\
$\sigma_{s e}$ & sheltering & $112.5-157.4$ & 1000 & EU-DEM v.1 \\
$\sigma_{s}$ & sheltering & $157.5-202.4$ & 1000 & EU-DEM v.1 \\
$\sigma_{s w}$ & sheltering & $202.5-247.4$ & 1000 & EU-DEM v.1 \\
$\sigma_{w}$ & sheltering & $247.5-292.4$ & 1000 & EU-DEM v.1 \\
$\sigma_{n w}$ & sheltering & $292.5-337.4$ & 1000 & EU-DEM v.1 \\
$\sigma_{s u m}$ & sheltering & $1-360$ & 1000 & EU-DEM v.1 \\
\hline
\end{tabular}

\subsection{LS-Boost Modeling (LSBoost) and Thin Plate Spline Interpolation (TPS)}

The $R R$ percentiles $\left(R R_{p}\right)$, being $p=\{1,5,10,15,20,25,30,35,40,45,50,55,60,65,70,75,80,85,90$, 95, 99\}, were modeled in a two-step procedure: (1) A least-squares boosting (LSBoost) algorithm was trained for RR included in DS1 using PV; and (2) the remaining DS1 residuals were further reduced by applying a thin plate spline interpolation (TPS). The modeling of $R R$ return times associated with greater $p>99$ (corresponding to a return period of 100 days) was omitted because they would exceed the limitations with which a reliable model can be developed given the length of the available dataset and would require an extreme value analysis [28].

The LSBoost model is a sequence of regression trees (B), i.e., decision trees with binary splits for regression [29-31]. The LSBoost model strives to reduce the mean squared error (MSE) between $R R_{p}$ and the aggregated $R R_{p}$ prediction $\left(\hat{R R_{p}}\right)$ of $B$. Starting with the median of $R R_{p}\left(\widetilde{R R}_{p}\right)$ of all DS1 stations, the regression trees $B_{1}, \ldots, B_{m}$ were combined in a weighted manner [29-31] to minimize MSE. Mathematically, the LSBoost algorithm is described as:

$$
\hat{R R_{p}}(P V)=\widetilde{R R}_{p}(P V)+v \sum_{m=1}^{M} p_{m} B_{m}(P V),
$$

where $p_{m}$ is the weight for model $m, M$ is the total number of regression trees, and $0<v \leq 1$ is the learning rate.

More than 5000 predictor variable combinations (PVC) were tested for their predictive power. Evaluation of the five-fold cross-validated $R^{2}$ revealed the most powerful PVC associated with DS1. The applied LSBoost algorithm was available from the Matlab ${ }^{\circledR}$ Software Statistics and Machine Learning Toolbox (Release 2019a; The Math Works Inc., Natick, MA, USA).

The predictors lon and lat, which describe the geographic location of a measurement station, were used as input for TPS [32]. The applied TPS algorithm was implemented in the Matlab ${ }^{\circledR}$ Software Curve Fitting Toolbox (Release 2019a; The Math Works Inc., Natick, MA, USA).

Wet days were defined when $\hat{R R} R_{p}>0\left(P R_{\text {wet }}\right)$. Wei, which was found to provide the best fitting accuracy, was fitted to $\hat{R} R_{p}$ on wet days applying the least-squares estimation method [33] The probability density function of Wei $(f(R R))$ is defined as [33]:

$$
f(R R ; \alpha, k)=\frac{k}{\alpha}\left(\frac{R R}{\alpha}\right)^{k-1} \exp \left[-\left(\frac{R R}{\alpha}\right)^{k}\right]
$$


where $k$ is the shape parameter and $\alpha$ is the scale parameter. From $P R_{\text {wet }}$ and $f(R R)$, the mean monthly precipitation sum $\left(\overline{R R}_{\text {sum }}\right)$ was then calculated:

$$
\overline{R R}_{\text {sum }}=\alpha \Gamma\left(1+\frac{1}{k}\right) \cdot n m \cdot R R_{\text {wet }},
$$

where $\Gamma$ is the Gamma function and $n m$ is the number of days per month.

After completion of $R R_{p}$ modeling and distribution fitting, the model was validated for $\overline{R R}_{\text {sum }}$ calculation using DS2. The model quality was assessed by applying $R^{2}$, mean absolute error $(M A E)$, and mean error $(M E)$.

\subsection{Inter-Area Variability}

The variability of $R R_{\text {sum }}$ within the study area was quantified by the interarea variability (IAV) according to:

$$
I A V=\frac{S}{\left\langle\overline{R R}_{\text {sum }}\right\rangle},
$$

where $S$ is the standard deviation of $\overline{R R}_{\text {sum }}$, and $\left\langle\overline{R R}_{\text {sum }}\right\rangle$ is the mean of $\overline{R R}_{\text {sum }}$ in the study area.

\section{Results and Discussion}

\subsection{Proportion of Wet Days $\left(P R_{\text {wet }}\right)$}

The monthly $P R_{\text {wet }}$ is displayed in Figure 3. The mean $P R_{\text {wet }}$ in the study area $\left(\left\langle P R_{\text {wet }}\right\rangle\right)$ was lowest $\left(\left\langle P R_{\text {wet }}\right\rangle=33 \%\right)$ in April (Figure 3d) and highest $\left(\left\langle P R_{\text {wet }}\right\rangle=44 \%\right)$ in December (Figure 3l). In addition to the temporal $P R_{\text {wet }}$ variability, there was also a strongly pronounced spatial $P R_{\text {wet }}$ pattern. In January (Figure 3a), February (Figure 3b), March (Figure 3c), October (Figure 3j), November (Figure 3k), and December, the highest $P R_{\text {wet }}$ values occurred in the west $\left(P R_{\text {wet }}>50 \%\right)$. The precipitation in these months was mainly caused by precipitation fronts from the west. In contrast, in May (Figure 3e), June (Figure 3f), and July (Figure 3g), the highest $P R_{\text {wet }}$ values occurred in the Alps ( $P R_{\text {wet }}>50 \%$ ). During summer, the high $P R_{\text {wet }}$ values in this area were caused by a high frequency of convective precipitation events [34].

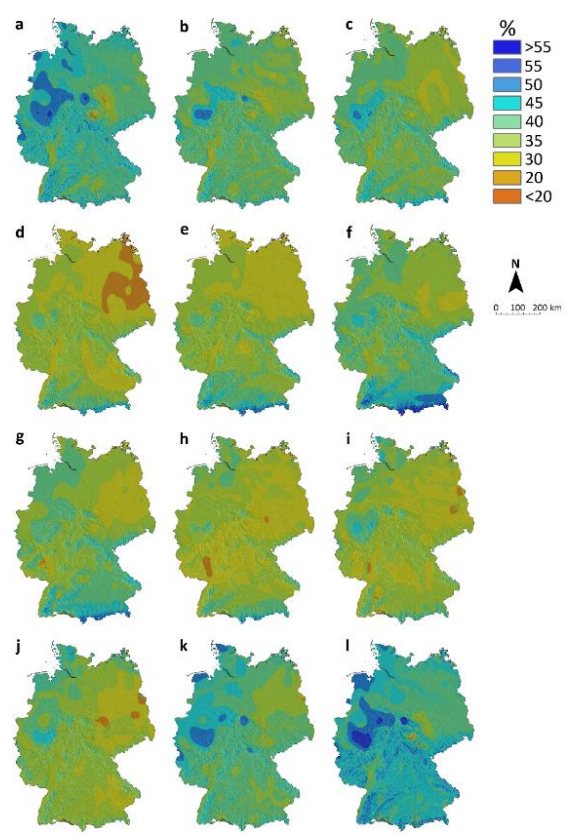

Figure 3. Monthly proportion of wet days ( $\left.P R_{\text {wet }}\right)$ in (a) January; (b) February; (c) March; (d) April; (e) May; (f) June; (g) July; (h) August; (i) September; (j) October; (k) November; and (l) December. 


\subsection{Distribution Fitting}

Results from the GoF evaluation are summarized in Figure 4 for all months. Out of the 18 candidate theoretical distributions, Gam, Wei, GP, and BS could be fitted to all empirical distributions in all months yielding accurate fits. All other theoretical distributions could either not be fitted to all $R R$ time series or their GoF was low.

According to $K S$, Wei was the best fitting theoretical distribution (Figure 4a). The median KS of Wei was 0.055 , the first quartile was 0.047 , and the third quartile was equal to 0.065 . For Gam, GP, and BS, median KS varied between 0.063 and 0.097. Similar results were found for $R_{P P}^{2}$ (Figure $4 \mathrm{~b}$ ). The median $R_{P P}^{2}$ for Wei was 0.996 and was thus close to a perfect match between the theoretical and empirical distribution. For Gam and GP, the median $R_{P P}^{2}$ was only slightly worse (0.994 resp. 0.995). The outliers obtained by Wei were not lower than 0.97 , indicating a reliable fitting accuracy. The third calculated GoF confirms the capability of Wei to mimic $f(R R)$ (Figure $4 c$ ). Its median $R_{Q Q}^{2}$ was 0.992 . A similarly high GoF could only be achieved by Gam (median of $R_{Q Q}^{2}=0.991$ ). Based on the GoF evaluation, Wei was assumed to be generally able to reproduce $f(R R)$ on wet days.
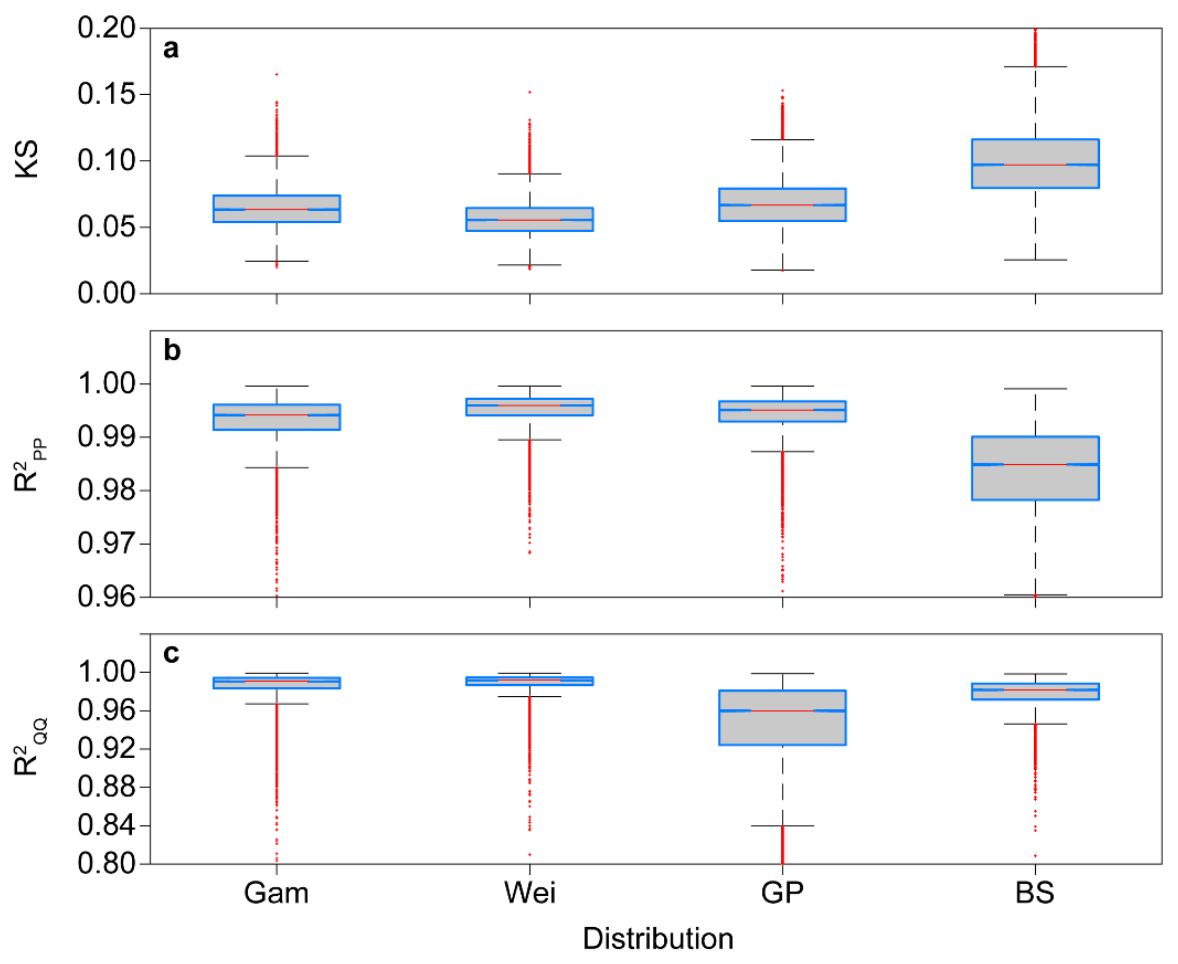

Figure 4. Goodness-of-fit (GoF) of theoretical distributions fitted to daily precipitation $(R R)$ on wet days evaluated by (a) the Kolmogorov-Smirnov statistic $(K S)$; (b) the coefficient of determination related to the cumulative probabilities $\left(R_{P P}^{2}\right)$; (c) the coefficient of determination related to the quantiles $\left(R_{Q Q}^{2}\right)$. The boxplots include results from all DS1 measurement stations and months.

All of the $R R$ probability density functions had similar shapes. In general, (1) the lowest $R R$ values have the highest probability density, and (2) the probability density decreases with increasing $R R$. As an example of the coincidence of the empirical probability density and Wei, the results for two different locations in summer (Jun-Aug, JJA) and winter (Dec-Feb, DJF) are presented in Figure 5.

For the city of Grünow, which is located in the northeast of the study area, $f(R R)$ is shown for August (Figure 5a). From this, it can be inferred that Grünow was very dry during summer. The frequency of $R R<1.5 \mathrm{~mm}$ was highest (0.305). During summer, $R R$ rarely exceeded $20 \mathrm{~mm}(0.027)$. The Wei function reproduced the shape of the histograms very accurately. 
The second example shows $f(R R)$ in August for Germany's highest peak, the Zugspitze (Figure $5 b$ ). Overall, the probability density of high $R R$ was much higher compared to Grünow. For instance, $f(R R$ $=0 \mathrm{~mm})$ was 0.148 and $f(R R>20 \mathrm{~mm})$ was 0.125 .

In December, the probability density of low $R R$ values increased in Grünow (Figure $5 c$ ), with $f(R R)$ $=1 \mathrm{~mm}$ being 0.42 . The exceedance probability of $10.4 \mathrm{~mm}$ was only 0.01 , indicating that high $R R$ values were extremely rare.

On the Zugspitze, the differences between $f(R R)$ in August and $f(R R)$ in December were marginal (Figure $5 \mathrm{~d}$ ). The probability density of $f(R R)>10.4 \mathrm{~mm}$ was even higher (0.35) in December. The examples show a broad spectrum of different $R R$ regimes. Nevertheless, the fitting of Wei was always very close to the empirical histogram.
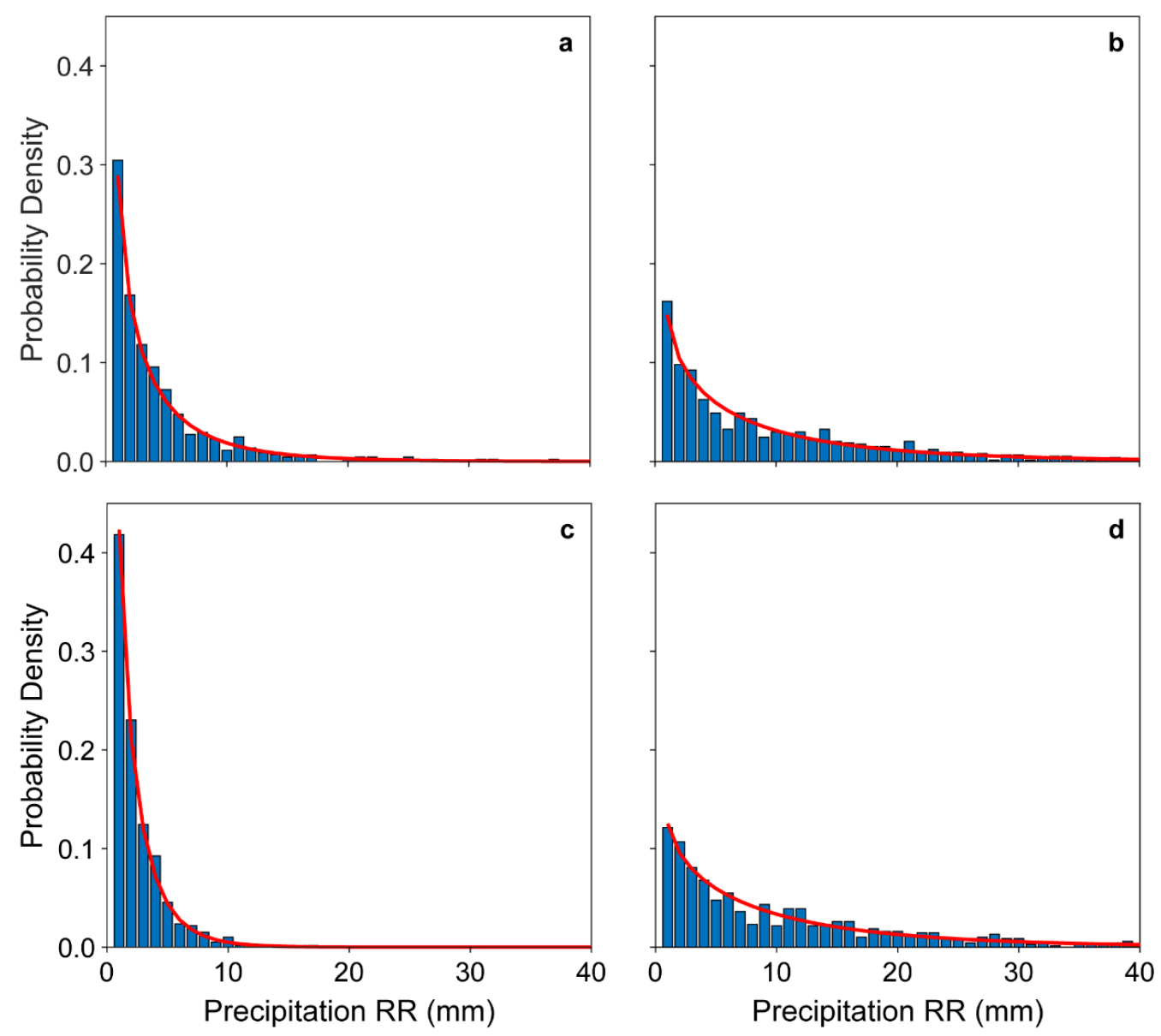

Figure 5. Weibull (Wei) probability density functions fitted to the empirical daily precipitation $(R R)$ on wet days in (a) Grünow in August; (b) Zugspitze in August, (c) Grünow in December; (d) Zugspitze in December.

\subsection{Heavy Precipitation}

As an example of heavy precipitation, $\hat{R R}_{99}$ is shown in Figure 6. It corresponds to a return period of 100 days. Similar to $P R_{w e t}$, summer months were more precipitous than all other months. In July, the highest $\hat{R R} R_{99}$ values generally occurred. The mean $\hat{R} R_{99}$ in the study area $\left(\left\langle\hat{R R} \hat{R}_{99}\right\rangle\right)$ in July was equal to $28.3 \mathrm{~mm}$ (Figure $6 \mathrm{~g}$ ). In contrast, $\left\langle\hat{R R} \hat{9}_{99}\right\rangle$ in February was only $16.0 \mathrm{~mm}$ (Figure 6b). In May and September, $\left\langle\hat{R R}{ }_{99}\right\rangle$ corresponded to $23.3 \mathrm{~mm}$, whereas in March, April, and November, $\left\langle\hat{R R}{ }_{99}\right\rangle<20 \mathrm{~mm}$. 

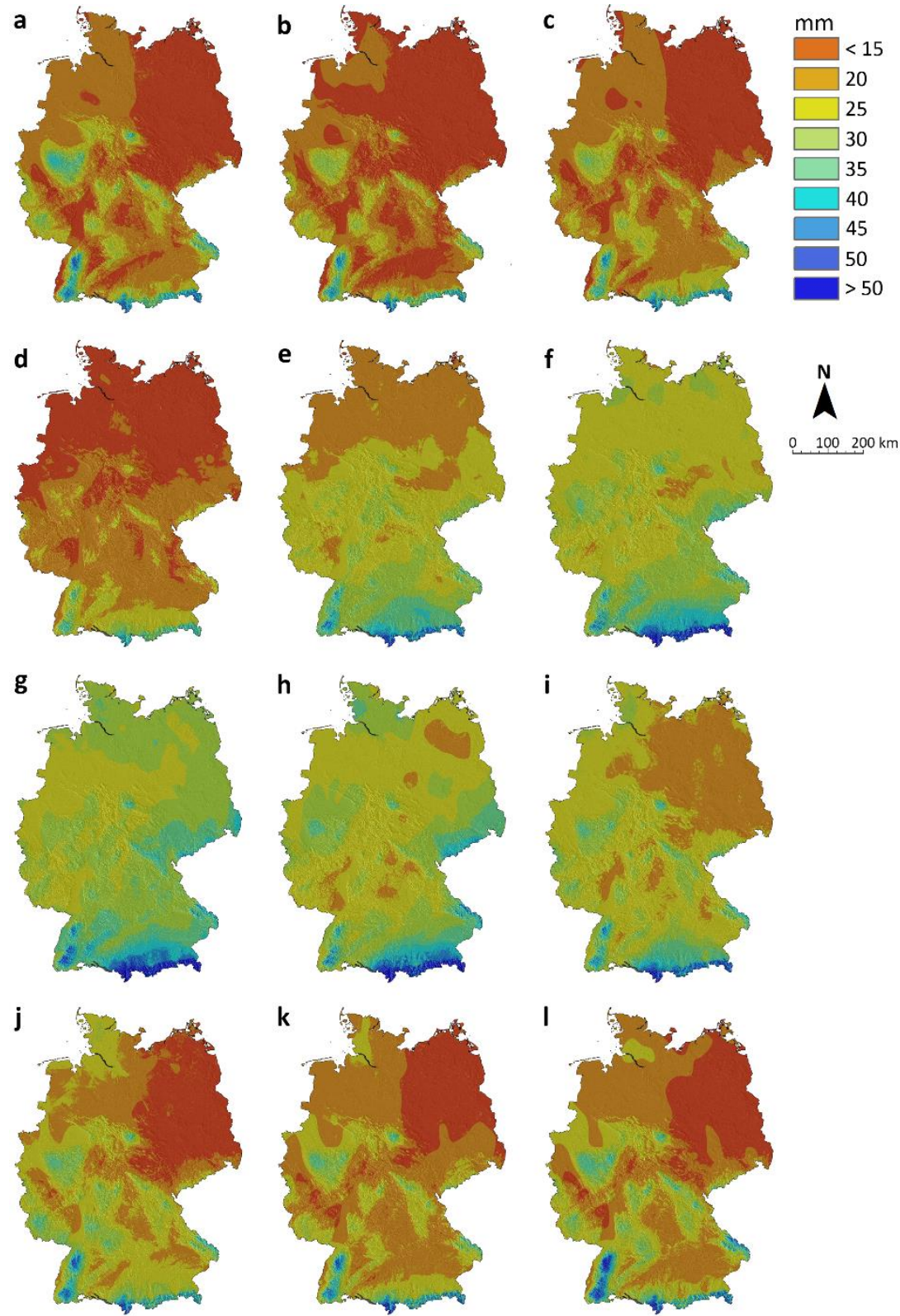

Figure 6. Heavy precipitation indicated by the $99^{\text {th }}$ percentile of daily precipitation $(\hat{R R} 99)$ in (a) January;

(b) February; (c) March; (d) April; (e) May; (f) June; (g) July; (h) August; (i) September; (j) October;

(k) November; (1) December.

The $\hat{R R}_{99}$ gradient in DJF is west-east oriented whereas in the summer months it is more northwest-southeast oriented. An important reason for this could be that heavy precipitation in winter is mainly stratiform [35] and predominantly from western directions. In summer, precipitation is predominantly convective. However, there are also regions in DJF were $\hat{R}_{99}$ is very high. In the low mountain ranges, especially on their west-east oriented slopes, $\hat{R} \hat{R}_{99}$ is often higher in winter than in the summer. In December, $\hat{R R}_{99}$ frequently exceeds $50 \mathrm{~mm}$ in the Black Forest and near the Alps (Figure 61). By comparison, in eastern Germany, $\hat{R R}{ }_{99}$ is clearly lower at less than $15 \mathrm{~mm}$. Overall, the $\hat{R R}{ }_{99}$ variability is greater in winter than in summer. This indicates that the small-scale properties of the orography determine the heavy precipitation pattern in winter. 


\subsection{Monthly and Annual Precipitation Sums}

In Figure $7, \overline{R R}_{\text {sum }}$ is presented. The large-scale spatial pattern shows similarities to the $\hat{R R}_{99}$ pattern. In January (Figure 7a) and December (Figure 71 ), $\overline{R R}_{\text {sum }}$ was highest on the west-east oriented slopes of the western low mountain ranges, where it often exceeded $150 \mathrm{~mm}$. In contrast, in the eastern parts of Germany, $\overline{R R}_{\text {sum }}$ was frequently below $50 \mathrm{~mm}$.
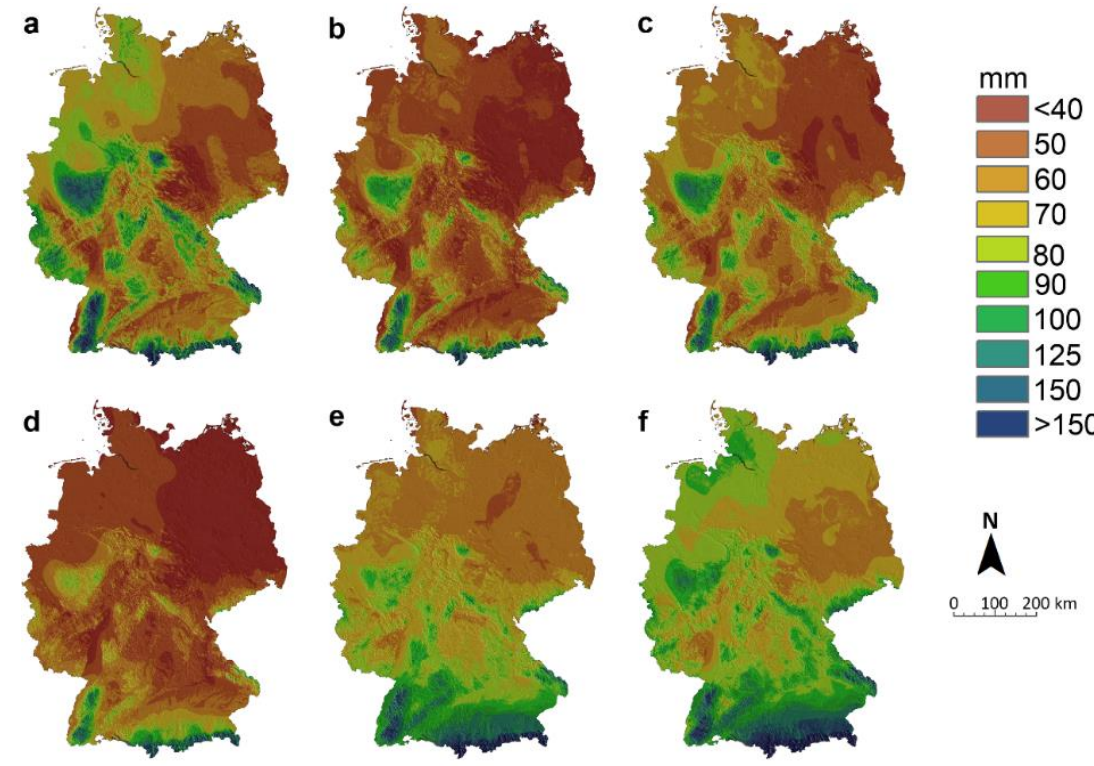

125

150

$>150$
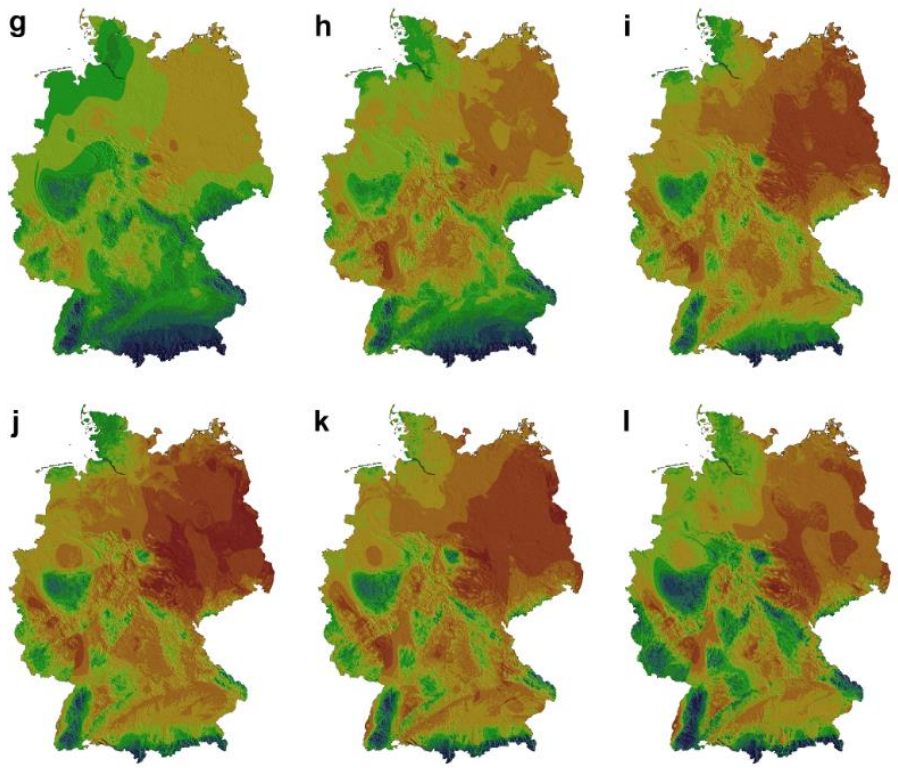

\section{A}

$0 \quad 100 \quad 200 \mathrm{~km}$

Figure 7. Mean monthly precipitation sum $\left(\overline{R R}_{\text {sum }}\right)$ in (a) January; (b) February; (c) March; (d) April; (e) May; (f) June; (g) July; (h) August; (i) September; (j) October; (k) November; (1) December.

In the study area, $\overline{R R}_{\text {sum }}$ was highest $\left(\left\langle\overline{R R}_{\text {sum }}\right\rangle=84 \mathrm{~mm}\right)$ in July (Figure $\left.7 \mathrm{~g}\right)$ and lowest $\left(\left\langle\overline{R R}_{\text {sum }}\right\rangle=\right.$ $49 \mathrm{~mm}$ ) in April (Figure $7 \mathrm{~d})$. The annual $\overline{R R}_{\text {sum }}$ cycle in the study area had two maxima: One in July and a second in December. At the regional scale, the annual $\overline{R R}_{\text {sum }}$ cycle may differ from $\left\langle\overline{R R}_{\text {sum }}\right\rangle$. For instance, in the vicinity of the Alps, $\overline{R R}_{\text {sum }}$ was often more than twice as high in JJA compared to DJF. In contrast, in some areas of the western low mountain ranges, the maximum $\overline{R R}_{\text {sum }}$ was modeled in December.

The interarea variability of $\overline{R R}_{\text {sum }}$ in the study area was highest $(I A V=3.6)$ in September (Figure 7i), October (Figure 7j), and November (Figure 7k). This indicates that both the large-scale and orographic 
influence on $\overline{R R}_{\text {sum }}$ in these months were strong. In contrast, $\overline{R R}_{\text {sum }}$ was more evenly distributed (IAV $=2.9$ ) in April (Figure 7d).

The mean annual precipitation sum $\left(\overline{R R}_{\text {sum, } y r}\right)$ is displayed in Figure 8 . In the study area, it corresponded to $\left\langle\overline{R R}_{\text {sum }, y r}\right\rangle=790 \mathrm{~mm}$ and tended to increase toward the south and decrease toward the east. In most of the low mountain ranges, $\overline{R R}_{\text {sum }, y r}$ usually exceeded $1000 \mathrm{~mm}$. In the southern low mountain ranges and close to the Alps, $\overline{R R}_{\text {sum }, y r}$ often exceeded $1500 \mathrm{~mm}$. At individual sites, $\overline{R R}_{\text {sum }, y r}$ may even be higher than $2000 \mathrm{~mm}$.

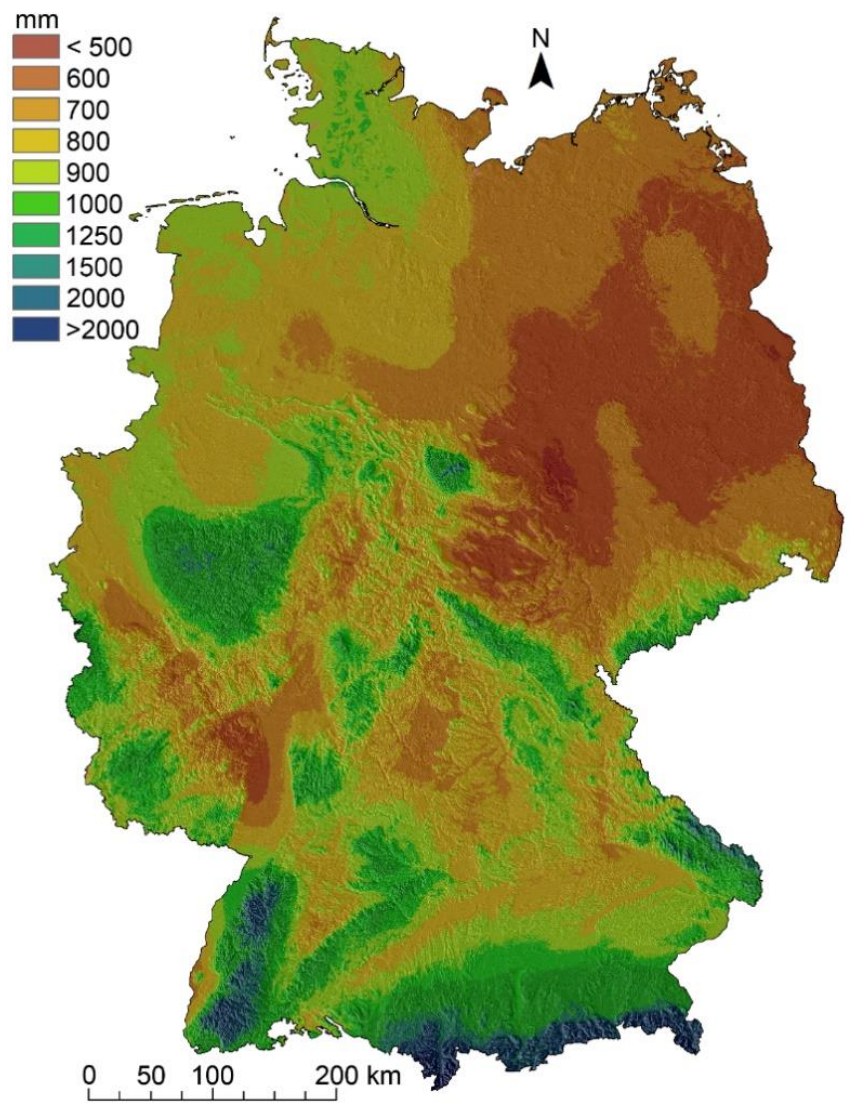

Figure 8. Mean annual precipitation sum $\left(\overline{R R}_{\text {sum, } y r}\right)$.

\subsection{Orographic Influence on Precipitation Sums}

The small-scale variability of precipitation over the course of the year is highlighted for the low mountain range of the Black Forest in Figure 9 . In January, $\overline{R R}_{\text {sum }}$ varied from $\approx 50 \mathrm{~mm}$ to almost $200 \mathrm{~mm}$ over a distance of less than $30 \mathrm{~km}$ (Figure 9a). The highest $\overline{R R}_{\text {sum }}$ values occurred on the high mountain slopes exposed to the west. The lowest $\overline{R R}_{\text {sum }}$ values can be found in the lowest regions of the map extract. The spatial pattern of $\overline{R R}_{\text {sum }}$ remained similar in April (Figure 9b). However, the $\overline{R R}_{\text {sum }}$ variability decreased compared to January. This was mainly due to the fact that $\overline{R R}_{\text {sum }}$ was lower at high elevations compared to January. In July, $\overline{R R}_{\text {sum }}$ increased in the entire study area (Figure 9c). In almost the entire map extract, $\overline{R R}_{\text {sum }}>90 \mathrm{~mm}$. In the high elevation regions, $\overline{R R}_{\text {sum }}$ was slightly lower compared to January. In October, $\overline{R R}_{\text {sum }}$ tendencies remained similar to the other months (Figure 9d). $\overline{R R}_{\text {sum }}$ ranged from $75 \mathrm{~mm}$ to $160 \mathrm{~mm}$. From the presented figure, it can be deduced that (1) elevation had a significant influence on $\overline{R R}_{\text {sum }}$ and (2) its effect on $\overline{R R}_{\text {sum }}$ varied over the course of the year.

To quantify the dependency of $\overline{R R}_{\text {sum }}$ on $\varepsilon$, boxplots of $\overline{R R}_{\text {sum }}$ as a function of $\varepsilon$ are shown in Figure 10. In January, $\overline{R R}_{\text {sum }}$ increased only slightly, with increasing $\varepsilon$ until $600 \mathrm{~m}$ (Figure 10a). Above $800 \mathrm{~m}, \overline{R R}_{\text {sum }}$ rapidly increased. At $\varepsilon>1200 \mathrm{~m}, \overline{R R}_{\text {sum }}$ remained quasi-constant. The variability of 
$\overline{R R}_{\text {sum }}$ was greatest at $\varepsilon \approx 1200 \mathrm{~m}$. A possible reason for this is that the orographic features (e.g., orientation, inclination) are very diverse in this elevation range.
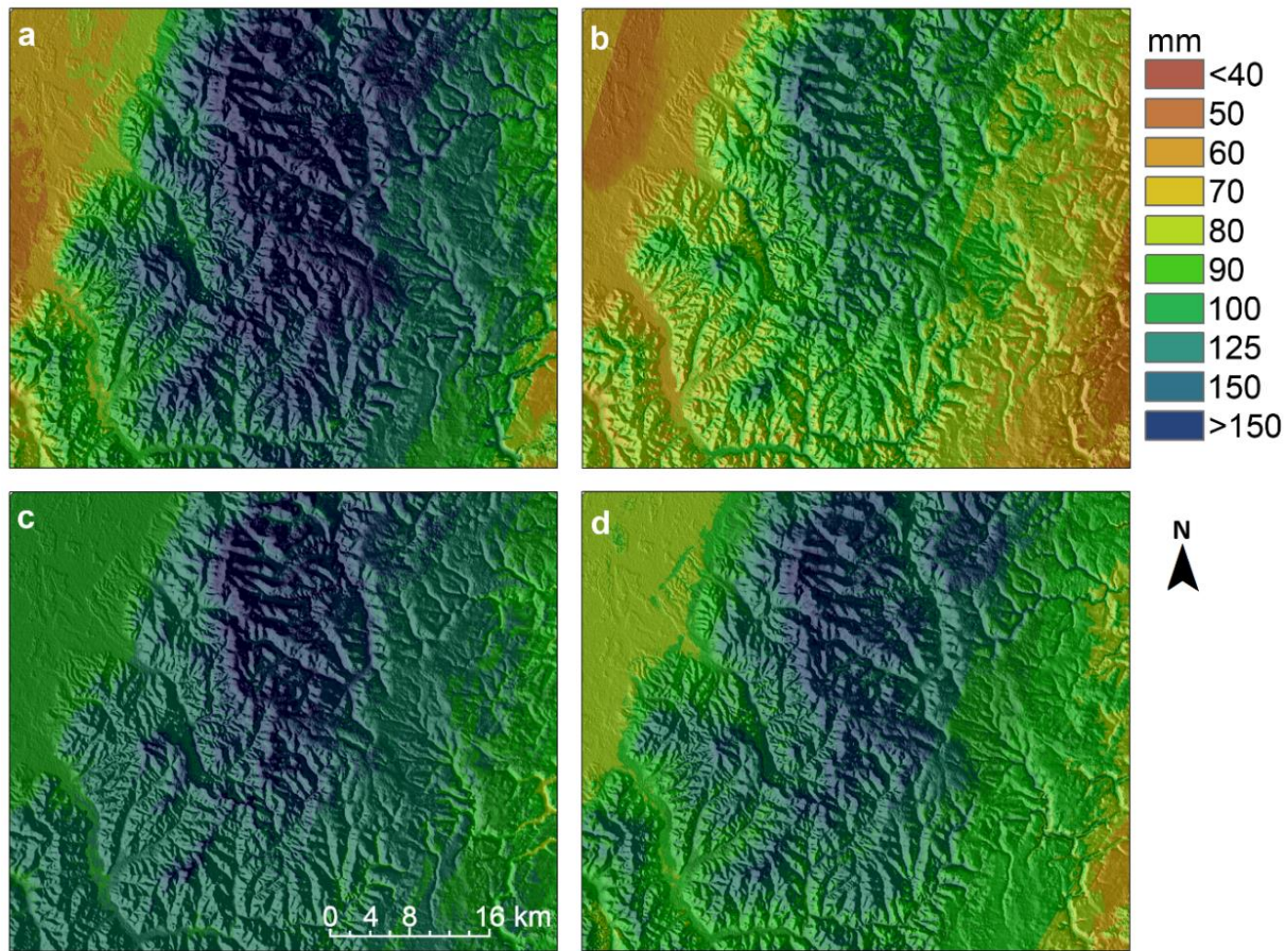

Figure 9. Map extracts displaying the mean monthly precipitation sum $\left(\overline{R R}_{\text {sum }}\right)$ in (a) January; (b) April; (c) July; (d) October in the low mountain range of the Black Forest.
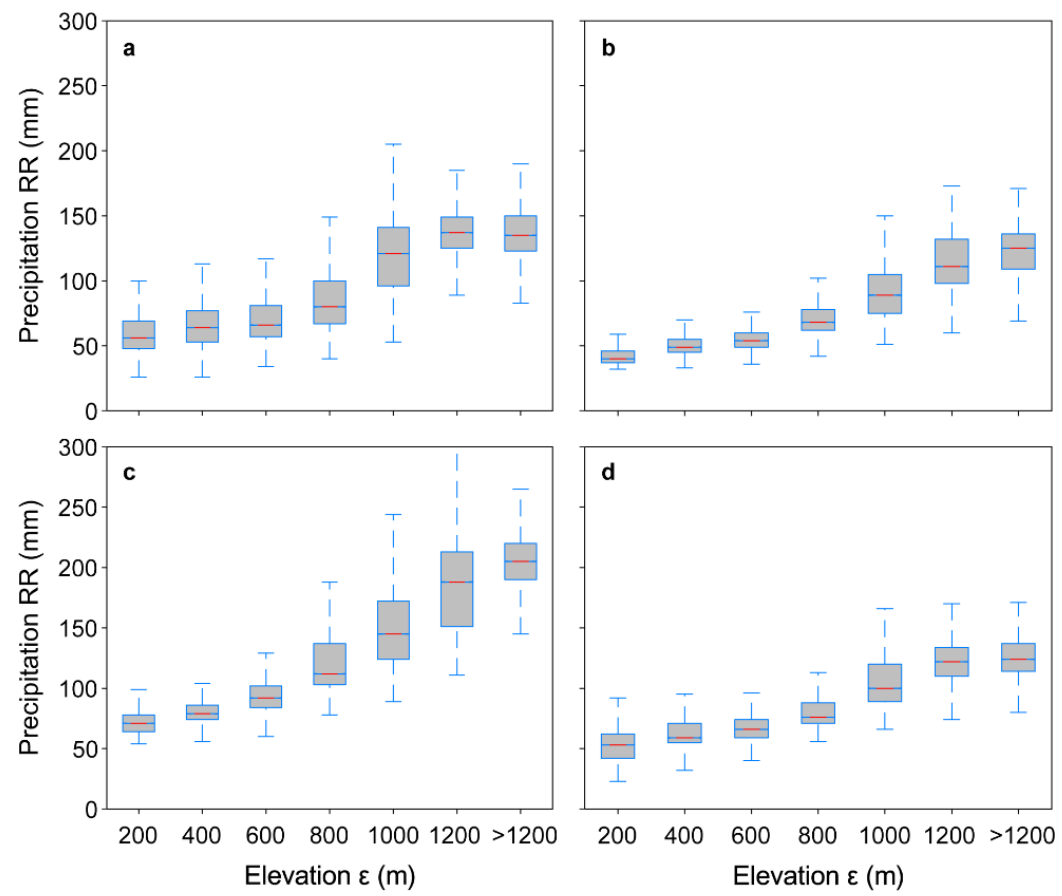

Figure 10. Boxplots of the mean monthly precipitation sum $\left(\overline{R R}_{\text {sum }}\right)$ as a function of elevation $(\varepsilon)$ in (a) January; (b) April; (c) July; (d) October. 
In April, the interquartile range of $\overline{R R}_{\text {sum }}$ was lower, especially at low $\varepsilon$ (Figure $10 \mathrm{~b}$ ). In July, the rate of $\overline{R R}_{\text {sum }}$ change as a function of $\varepsilon$ was greatest (Figure 10c). The median $\overline{R R}_{\text {sum }}$ increased from $71 \mathrm{~mm}$ at $\varepsilon=200 \mathrm{~m}$ to $205 \mathrm{~mm}$ at $\varepsilon>1200 \mathrm{~m}$. In addition, $\overline{R R}_{\text {sum }}$ variability also increased. Both the general $\overline{R R}_{\text {sum }}$ level and the variability of $\overline{R R}_{\text {sum }}$ decreased in October (Figure 10d). The median of $\overline{R R}_{\text {sum }}$ increased from $53 \mathrm{~mm}$ at $\varepsilon=200 \mathrm{~m}$ to $124 \mathrm{~mm}$ at $\varepsilon>1200 \mathrm{~m}$.

\subsection{Model Validation}

Results from model validation are summarized in Table 3. From this summary, it can be seen that the $R^{2}$ ranged from 0.70 in February to 0.87 in June and July. In 11 months, the $R^{2}$ exceeded 0.75 . From May to September, $R^{2}>0.80$, which indicates that the accuracy of the model used to simulate $\overline{R R}_{\text {sum }}$ was higher in summer than in winter. The $\overline{R R}_{\text {sum }, y r}$ model had the highest accuracy $\left(R^{2}=0.91\right)$. Further, $M A E$ indicates that the accuracy of the models was very good (below $10 \mathrm{~mm}$ in all months). For $\overline{R R}_{\text {sum }, y r}, M A E=9 \mathrm{~mm}$. ME indicates that there was no bias in the models, because it was either $0 \mathrm{~mm}$ or $1 \mathrm{~mm}$ in all months and on the annual scale.

Table 3. Model validation evaluated by the coefficient of determination $\left(R^{2}\right)$, the mean absolute error $(M A E)$, and mean error $(M E)$ calculated for the mean monthly precipitation sum $\left(\overline{R R}_{\text {sum }}\right)$ and the mean annual precipitation sum $\left(\overline{R R}_{\text {sum, yr }}\right)$.

\begin{tabular}{cccc}
\hline Month & $\boldsymbol{R}^{\mathbf{2}}$ & $\boldsymbol{M A E} \mathbf{( \mathbf { m m } )}$ & $\boldsymbol{M E} \mathbf{( m m )}$ \\
\hline January & 0.78 & 9 & 1 \\
February & 0.70 & 8 & 1 \\
March & 0.76 & 9 & 1 \\
April & 0.75 & 7 & 1 \\
May & 0.83 & 8 & 0 \\
June & 0.87 & 8 & 0 \\
July & 0.87 & 9 & 0 \\
August & 0.85 & 8 & 0 \\
September & 0.80 & 8 & 0 \\
October & 0.79 & 8 & 1 \\
November & 0.75 & 8 & 0 \\
December & 0.78 & 9 & 0 \\
Year & 0.91 & 9 & 1 \\
\hline
\end{tabular}

\section{Conclusions}

In this study, daily precipitation was modeled monthly at a very high resolution in Germany. It was demonstrated that the annual precipitation cycle depends on regions and orographic properties such as elevation, relative elevation, and topographic sheltering. The high resolution provided the foundation for a very detailed detection of local precipitation regimes. According to the rigorous goodness-of-fit evaluation using a parametrization dataset and a validation dataset, the accuracy of the models built was good. The coefficient of determination reached values up to 0.91 , which was achieved by evaluating the results from modeling the mean annual precipitation sum.

One important feature of GePrA is that it is not limited to the mapping of large-scale precipitation patterns. It can also be used to quantify the effects of the local orography on monthly and annual precipitation. Moreover, GePrA does not only reproduce the monthly and annual precipitation sums, but also the entire monthly precipitation distributions. The two parameters of the Weibull distribution used to fit the empirical precipitation distributions and the share of wet days are available monthly for all grid cells in the study area. Using the monthly Weibull parameters and the share of wet days, it was possible to calculate any percentile and the monthly precipitation sum.

Although the developed models reflect the monthly distribution of precipitation very well, the results and the approach are not without limitations. GePrA does not indicate precipitation intensity on sub-monthly scales. The statistical approach of GePra does not allow the mapping of 
daily precipitation conditions. No direct relationship can be established between individual synoptic conditions and the simulated precipitation sums. Furthermore, it is not possible to map extreme heavy precipitation events with return periods exceeding 100 days. It is possible to transfer the proposed approach to the analysis of extreme precipitation events, but that would require longer time series than those used in this study.

Author Contributions: C.J. and D.S. developed the research idea, carried out data analysis and wrote the manuscript.

Funding: This work was supported by the Federal Ministry for the Environment, Nature Conservation and Nuclear Safety within the framework of the Forest Climate Fund (MiStriKli 28W-K-4-166-01).

Conflicts of Interest: The authors declare no conflict of interest.

\section{References}

1. Iqbal, M.F.; Athar, H. Validation of satellite based precipitation over diverse topography of Pakistan. Atmos. Res. 2018, 201, 247-260. [CrossRef]

2. Zuo, J.; Xu, J.; Chen, Y.; Wang, C. Downscaling Precipitation in the Data-Scarce Inland River Basin of Northwest China Based on Earth System Data Products. Atmosphere 2019, 10, 613. [CrossRef]

3. Yang, T.; Shao, Q.; Hao, Z.C.; Chen, X.; Zhang, Z.; Xu, C.Y.; Sun, L. Regional frequency analysis and spatio-temporal pattern characterization of rainfall extremes in the Pearl River Basin, China. J. Hydrol. 2010, 380, 386-405. [CrossRef]

4. Putniković, S.; Tošić, I. Relationship between atmospheric circulation weather types and seasonal precipitation in Serbia. Meteorol. Atmos. Phys. 2018, 130, 393-403. [CrossRef]

5. Hiebl, J.; Frei, C. Daily precipitation grids for Austria since 1961—Development and evaluation of a spatial dataset for hydroclimatic monitoring and modelling. Theor. Appl. Climatol. 2018, 132, 327-345. [CrossRef]

6. Henn, B.; Newman, A.J.; Livneh, B.; Daly, C.; Lundquist, J.D. An assessment of differences in gridded precipitation datasets in complex terrain. J. Hydrol. 2018, 556, 1205-1219. [CrossRef]

7. Herrnegger, M.; Senoner, T.; Nachtnebel, H.P. Adjustment of spatio-temporal precipitation patterns in a high Alpine environment. J. Hydrol. 2018, 556, 913-921. [CrossRef]

8. Basist, A.; Bell, G.D.; Meentemeyer, V. Statistical relationships between topography and precipitation patterns. J. Climate 1994, 7, 1305-1315. [CrossRef]

9. Yu, H.; Wang, L.; Yang, R.; Yang, M.; Gao, R. Temporal and spatial variation of precipitation in the Hengduan Mountains region in China and its relationship with elevation and latitude. Atmos. Res. 2018, 213, 1-16. [CrossRef]

10. Sun, Q.; Miao, C.; Duan, Q.; Ashouri, H.; Sorooshian, S.; Hsu, K.L. A review of global precipitation data sets: Data sources, estimation, and intercomparisons. Rev. Geophys. 2018, 56, 79-107. [CrossRef]

11. Perugini, L; Caporaso, L.; Marconi, S.; Cescatti, A.; Quesada, B.; de Noblet-Ducoudre, N.; House, J.I.; Arneth, A. Biophysical effects on temperature and precipitation due to land cover change. Environ. Res. Lett. 2017, 12, 053002. [CrossRef]

12. López-Espinoza, E.; Ruiz-Angulo, A.; Zavala-Hidalgo, J.; Romero-Centeno, R.; Escamilla-Salazar, J. Impacts of the Desiccated Lake System on Precipitation in the Basin of Mexico City. Atmosphere 2019, 10, 628. [CrossRef]

13. Ghada, W.; Yuan, Y.; Wastl, C.; Estrella, N.; Menzel, A. Precipitation Diurnal Cycle in Germany Linked to Large-Scale Weather Circulations. Atmosphere 2019, 10, 545. [CrossRef]

14. Long, Q.; Chen, Q.; Gui, K.; Zhang, Y. A Case Study of a Heavy Rain over the Southeastern Tibetan Plateau. Atmosphere 2016, 7, 118. [CrossRef]

15. Tang, G.; Behrangi, A.; Long, D.; Li, C.; Hong, Y. Accounting for spatiotemporal errors of gauges: A critical step to evaluate gridded precipitation products. J. Hydrol. 2018, 559, 294-306. [CrossRef]

16. Faiz, M.A.; Liu, D.; Fu, Q.; Sun, Q.; Li, M.; Baig, F.; Li, T.; Cui, S. How accurate are the performances of gridded precipitation data products over Northeast China? Atmos. Res. 2018, 211, 12-20. [CrossRef]

17. Baker, L.H.; Shaffrey, L.C.; Scaife, A.A. Improved seasonal prediction of UK regional precipitation using atmospheric circulation. Int. J. Climatol. 2018, 38, 437-453. [CrossRef] 
18. Ehmele, F.; Kunz, M. Flood-related extreme precipitation in southwestern Germany: development of a two-dimensional stochastic precipitation model. Hydrol. Earth Syst. Sc. 2019, 23, 1083-1102. [CrossRef]

19. Zhang, T.; Li, B.; Yuan, M.; Gao, X.; Sun, Q.; Xu, L.; Jiang, Y. Spatial downscaling of TRMM precipitation data considering the impacts of macro-geographical factors and local elevation in the Three-River Headwaters Region. Remote Sens. Environ. 2018, 215, 109-127. [CrossRef]

20. Jung, C.; Schindler, D. Development of a statistical bivariate wind speed-wind shear model (WSWS) to quantify the height-dependent wind resource. Energy Convers. Manage. 2017, 149, 303-317. [CrossRef]

21. CDC (Climate Data Center). Available online: https://cdc.dwd.de/portal/ (accessed on 28 May 2019).

22. Martinez-Villalobos, C.; Neelin, J.D. Why do precipitation intensities tend to follow Gamma distributions? J. Atmos. Sci. 2019, 76, 3611-3631. [CrossRef]

23. Papalexiou, S.M.; Koutsoyiannis, D. A global survey on the seasonal variation of the marginal distribution of daily precipitation. Adv. Water Resour. 2016, 94, 131-145. [CrossRef]

24. Jung, C.; Schindler, D. Sensitivity analysis of the system of wind speed distributions. Energy Convers. Manag. 2018, 177, 376-384. [CrossRef]

25. Jung, C.; Schindler, D. Global comparison of the goodness-of-fit of wind speed distributions. Energy Convers. Manage. 2017, 133, 216-234. [CrossRef]

26. EU DEM. Available online: https://land.copernicus.eu/imagery-in-situ/eu-dem (accessed on 28 May 2019).

27. Jung, C.; Schindler, D. Historical Winter Storm Atlas for Germany (GeWiSA). Atmosphere 2019, $10,387$. [CrossRef]

28. Marra, F.; Nikolopoulos, E.I.; Anagnostou, E.N.; Morin, E. Metastatistical Extreme Value analysis of hourly rainfall from short records: Estimation of high quantiles and impact of measurement errors. Adv. Water Resour. 2018, 117, 27-39. [CrossRef]

29. Friedman, J. Greedy function approximation: A gradient boosting machine. Ann. Stat. 2001, 29, 1189-1232. [CrossRef]

30. Van Heijst, D.; Potharst, R.; van Wezel, M. A support system for predicting eBay end prices. Decis. Support Syst. 2008, 44, 970-982. [CrossRef]

31. Jung, C.; Schindler, D. 3D statistical mapping of Germany's wind resource using WSWS. Energy Convers. Manaeg. 2018, 159, 96-108. [CrossRef]

32. Wood, S.N. Thin-plate regression splines. J. R. Stat. Soc. Ser. B 2003, 65, 95-114. [CrossRef]

33. Jung, C.; Schindler, D.; Laible, J.; Buchholz, A. Introducing a system of wind speed distributions for modeling properties of wind speed regimes around the world. Energy Convers. Manag. 2017, 144, 181-192. [CrossRef]

34. Giorgi, F.; Torma, C.; Coppola, E.; Ban, N.; Schär, C.; Somot, S. Enhanced summer convective rainfall at Alpine high elevations in response to climate warming. Nat. Geosci. 2016, 9, 584. [CrossRef]

35. Kyselý, J.; Rulfová, Z.; Farda, A.; Hanel, M. Convective and stratiform precipitation characteristics in an ensemble of regional climate model simulations. Clim. Dynam. 2016, 46, 227-243. [CrossRef] 